\title{
Silencing APRIL Gene by siRNA Leads to Inhibition of Proliferation and Cell Cycle Arrest in Gastric Cancer
}




\title{
Cell Line MGC-803 and SGC-7901
}

\author{
X. WANG AND B. LIU*
}

Department of Digestive Endoscopy, The Second Hospital of Jilin University, Jilin, China

Wang and Liu: Inhibition of Proliferation and Cell Cycle Arrest in Gastric Cancer Cells by siAPRIL

The aim of this study was to explore the effects of silencing a proliferation-inducing ligand on the growth and cell cycle of human gastric cancer cells. MGC-803 and SGC-7901 cells were infected with lenti-a proliferation-inducing ligand si and mRNA expression was analyzed by real-time polymerase chain reaction. Cell viability, colony formation and cell cycle stages were detected by MTT assay, colony forming assay and Cellomics ArrayScan, respectively. Results from real-time polymerase chain reaction indicated that lenti-a proliferation-inducing ligand-si greatly reduced the proliferation-inducing ligand mRNA expression in both cell lines. Cell viability and colony formation ability were significantly hampered. Moreover, cell cycle was arrested in both cell lines, elucidating the mechanism underlying the inhibitory effects of siRNA on cell proliferation. The present study indicated that lentivirus-mediated gene delivery might be a promising strategy in the treatment of gastric cancer.

Key words: APRIL, lentivirus, gastric cancer, RNA interference

Gastric cancer (GC) commonly referred to as stomach cancer can develop in any part of the stomach and may spread throughout the stomach and to other organs, particularly the oesophagus, lungs, lymph nodes and the liver. Despite a reduction in the rate of mortality, GC still ranks as the second most frequent cancer worldwide. There are about 1000000 new cases diagnosed and 800000 deaths worldwide each year ${ }^{[1,2]}$. The $5 \mathrm{y}$ survival rate for the curative surgical resection ranges from $30-50 \%$ for patients with stage II disease and from $10-25 \%$ for patients with stage III disease. The operative mortality rate for patients undergoing curative surgical resection at major academic centers is less than $3 \%{ }^{[3]}$. Understanding the molecular mechanisms underlying the initiation and progression of GC is important for prevention, early diagnosis and identifying novel therapeutic targets for GC.

A proliferation-inducing ligand (APRIL, also known as TALL-2, TRDL1, or TNFSF13), a member of tumor necrosis factor (TNF) family, was originally identified in cell lines and primary samples from various tumor lesions in 1998 and was named for its capacity to stimulate the proliferation of tumor cells in vitro and in vivo ${ }^{[4]}$. In contrast to most TNF family members, APRIL is processed in the Golgi apparatus into the active soluble form by a furin convertase ${ }^{[5]}$. APRIL is expressed by a subset of immune cells that also produce B-cell activating factor (BAFF), monocytes, macrophages, dendritic cells, neutrophils, activated B cells and T cells as well as in some non-immune cells such as epithelial cells and osteoclasts ${ }^{[4,6-8]}$. Moreover, APRIL is abundantly expressed in a variety of tumor cells and tissues, such as lung carcinoma, melanoma, lymphoid malignancies and in particular gastrointestinal tumors including rectum, duodenum, colon, stomach, lung, and oesophagus ${ }^{[9-17]}$.

Previous studies reported have further confirmed that APRIL mRNA and protein are overexpressed in GC tissues; yet, these are not expressed or weakly expressed in normal tissues ${ }^{[18-20]}$. To study the role of APRIL gene in the occurrence and development of GC, lentiviral vectors of RNAi targeting the human APRIL gene were constructed and the inhibitory effect of this construct on APRIL gene's short hairpin RNA (shRNA) was observed on the growth of human gastric cancer cell lines MGC-803 and SGC-7901 in vitro and in vivo.

The human APRIL cDNA sequence (Genbank accession number: NM_172088) was searched for suitable siRNA target palindromic sequences and aaTCCAGGATGCTGGAGTTTA was selected. DNA oligos containing the target palindromic sequences were chemically synthesized, annealed and inserted into the lentivirus gene transfer vector pLVTHM (Biovector Science $\mathrm{Lab}$ ) which encoded a green fluorescent protein (GFP) sequence by double digestion with Age I, EcoR $\mathrm{I}$, and ligation with T4 DNA ligase in accordance to the Biovector Science Lab's guidelines. The ligation was transformed into competent $E$. coli DH5 $\alpha$ cells. The correct transformant was identified by restriction 
enzyme analysis and DNA sequencing. As a control for APRIL siRNA, a corresponding non-silencing siRNA sequence (5'-TTCTCCGAACGTGTCACGT-3') was used.

293T cells and MGC-803 and SGC-7901 were purchased from the American Type Culture Collections. Cells were grown in $5 \% \mathrm{CO}_{2}$ saturated with humidity at $37^{\circ}$ and cultured as monolayer in RPMI 1640 supplemented with penicillin/streptomycin and $10 \%$ FBS. The recombinant virus lenti-APRILsi targeting APRIL and the control lentivirus, lenti-NC were produced by co-transfecting $293 \mathrm{~T}$ cells with the lentivirus expression plasmid and packaging helper plasmids (psPAX2 and pMD2.G, Biovector Science Lab) using Lipofectamine 2000 reagent according to the manufacturer's instructions. The lentiviral supernatant was harvested $48 \mathrm{~h}$ post-transfection, and the virus titre was determined by hole-by-dilution. MGC-803 and SGC-7901 cells were infected with recombinant lentivirus respectively at a multiplicity of infection (MOI) of 20.

Total RNA in MGC-803 and SGC-7901 cells were extracted with Trizol (Invitrogen, USA), and reverse transcription was then conducted with M-MLV reverse transcriptase (Promega, USA) at $42^{\circ}$ for 60 min according to the manufacturer's recommendation. The expression level of APRIL mRNA in these cell lines was analyzed by Real-time PCR using the SYBR green PCR master mix (TaKaRa) with the following program: $95^{\circ}$ for $15 \mathrm{~s}$, followed by 45 cycles consisting of $5 \mathrm{~s}$ at $95^{\circ}, 30 \mathrm{~s}$ at $60^{\circ}$. Primers used were as follows: APRIL (forward: 5'-GGTATCCCTGGCAGAGTC-3'; reverse: 5'-CTGTCACATCGGAGTCATC-3') and human $\quad \beta$-actin $\quad$ (forward: 5'-GGCGGCACCACCATGTACCCT-3'; reverse: 5'-AGGGGCCGGACTCGTCATACT-3'). The expression of APRIL was determined by normalization of the threshold cycle $(\mathrm{Ct})$ of APRIL to that of the control housekeeping gene $\beta$-actin. Data were analyzed using the 2- $\Delta \Delta \mathrm{CT}$ method ${ }^{[21]}$. All reactions were performed in triplicate.

Cell viability was assessed using the MTT assay. Briefly, gastric cancer cells MGC-803 and SGC-7901 were seeded in 96-well plates in complete culture medium at a density of 105 cells per well in triplicate for the Lenti-APRILsi and Lenti-NC groups. After 1, 2, 3, 4 and $5 \mathrm{~d}, 20 \mu \mathrm{l}$ of MTT $(5 \mathrm{mg} / \mathrm{ml}$; Sigma-Aldrich Corp.) was added and incubated for another $4 \mathrm{~h}$ at $37^{\circ}$. Then $150 \mu \mathrm{l}$ of dimethyl sulfoxide was added to each well and thoroughly mixed for $10 \mathrm{~min}$. Absorbance was measured at $570 \mathrm{~nm}$ using a Victor Multilabel Counter
(Model 1420 PerkinElmer). Cell growth was calculated as means of triplicate per group.

MGC-803 and SGC-7901 cells infected by lentivirus were digested with trypsin and seeded into 6 multiwell plates at 800 cells/well in triplicate. After culturing for $14 \mathrm{~d}$, colonies formed were fixed with paraformaldehyde for $30 \mathrm{~min}$ and stained with Giemsa stain solution (Sigma-Aldrich Corp.) for 20 min, pelleted by centrifugation, re-suspended in RPMI 1640 medium and counted using a micropublisher 3.3RTV (Olympus).

For each group, cells infected by lentivirus were washed with D-Hanks solution when the confluency was about $80 \%$, and then fixed for at least $1 \mathrm{~h}$ in $70 \%$ ethanol at $4^{\circ}$. Cells were then washed and stained with $50 \mu \mathrm{g} / \mathrm{ml}$ PI in the presence of $100 \mu \mathrm{g} / \mathrm{ml}$ RNase (SigmaAldrich Corp.). After $5 \mathrm{~min}$ at room temperature, the cells were analyzed by Cellomics ArrayScan VTI HCS Reader (Thermo Scientific Company) in triplicate for both groups.

The lentiviral vector system for expressing shRNAs directed against APRIL was used in this study. After a single exposure of SGC-803 cells to the encoding lentivirus, a high percent (more than 90) of transfectants expressed GFP at $72 \mathrm{~h}$ after the transfection as shown in figs. $1 \mathrm{a}$ and $1 \mathrm{~b}$, indicating a high and stable transfection of lentiviral vector system. Similar results were observed in SGC-7901 cells (data not shown).

In order to investigate the effect of lenti-APRILsi on the expression of APRIL mRNA, RT-PCR was performed. As shown in fig. 2, APRIL mRNA levels in lentiAPRILsi-infected MGC-803 and SGC-7901 cells were significantly reduced by 3 and 4 fold when compared

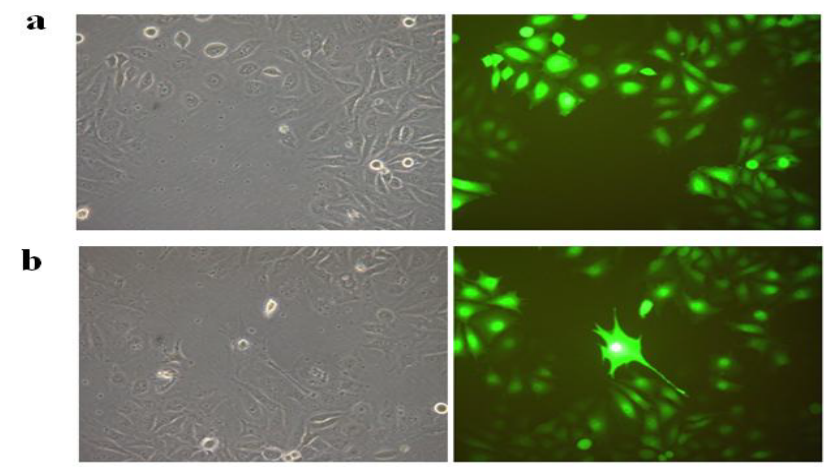

Fig. 1: Transfections of recombinant lentivirus with or without APRILsi.

a. Phase contrast (left) and GFP expression (right) in MGC-803 cells under fluorescent microscope $72 \mathrm{~h}$ after transfection with lenti-NC. b. Phase contrast (left) and GFP expression (right) in SGC-7901 cells under fluorescent microscope $72 \mathrm{~h}$ after transfection with lenti-APRILsi 
with that of in Lenti-NC infected-MGC-803 and SGC7901 cells, respectively.

As demonstrated in figs. $3 \mathrm{a}$ and $3 \mathrm{~b}$, after lenti-APRILsi infection, the viability of MGC-803 cells was evidently decreased at 2, 3, 4 and $5 \mathrm{~d}$, respectively, when compared to lenti-NC-infected MGC-803 cells. While the viability was not apparent difference between lenti-APRILsi-infected SGC-7901 cells and lenti-NC infected group at 2 and $3 \mathrm{~d}$ except in 4 and $5 \mathrm{~d}$, where the difference was significant.

The effect of lentivirus infection on colony forming ability was further examined. Results from colony formation assay as shown in figs. $4 a, b$, c and d indicated that introduction of lenti-APRILsi significantly reduced the numbers of MGC-803 and SGC-7901 cells, leading to significant inhibition of cell growth. To investigate the effects of lenti-APRILsi on cell cycle, $\mathrm{G}_{0} / \mathrm{G}_{1}, \mathrm{~S}, \mathrm{G}_{2} / \mathrm{M}$ phase cells were detected using Cellomics ArrayScan. As shown in fig. 4a, the numbers of lenti-APRILsiinfected MGC-803 cells in S phase or G2/M phase were significantly higher than that of lenti-NC-infected MGC-803 cells, while in $\mathrm{G}_{0} / \mathrm{G}_{1}$ phase, the number of lenti-APRILsi infected cells was significantly lower than that of lenti-NC infected cells. Similar results were observed with SGC-7901 cells, except in the S phase, where the number of lenti-APRILsi infected cells was

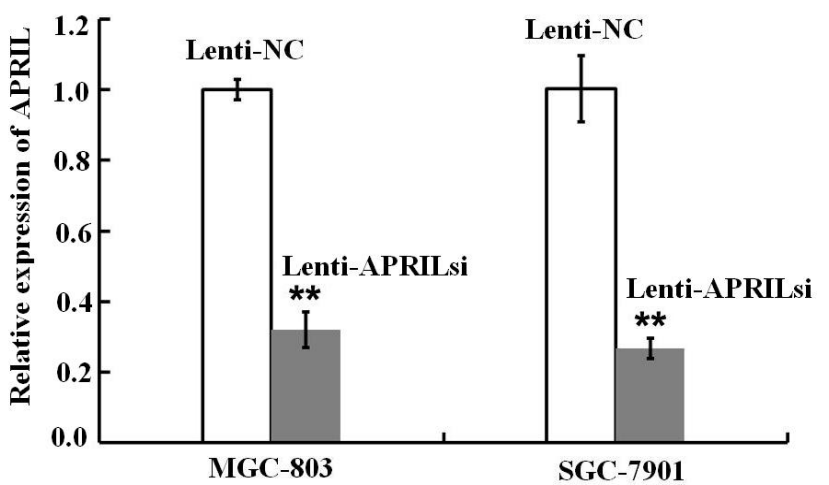

Fig. 2: Expression of APRIL in MGC-803 and SGC-7901 cells with or without lenti-APRILsi infection

*represents $\mathbf{p}<0.05$

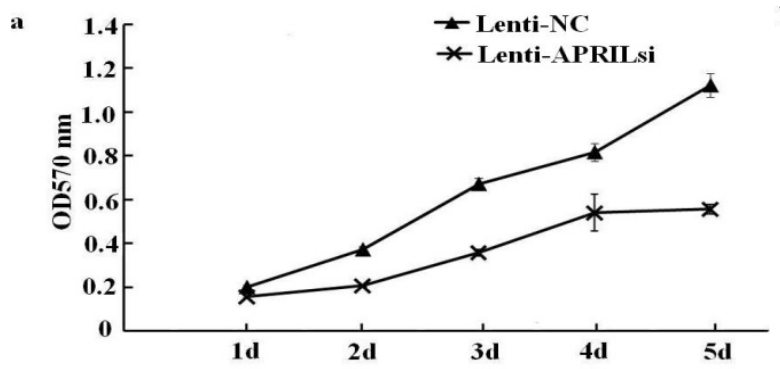

significantly lower than that of lenti-NC infected cells (fig. 5).

GC still represents a great healthcare burden all over the world. In the absence of strategies for early diagnosis and detection, GC continues to have poor prognosis ${ }^{[22]}$. During the course of cancer development, gene abnormality such as mutation or amplification, which might implicate tumor survival, progression and metastasis, can be detected frequently. In human $\mathrm{GC}$, a series of specific gene (oncogenes and tumorsuppressor genes) mutations are observed, including the APRIL gene.

As a new member of TNF superfamily, APRIL shares about $30 \%$ homology with BAFF (also known as B lymphocyte stimulator, BLyS, TALL-1 or THANK) from the TNF family. These share 2 receptors, B cell maturation antigen (BCMA) and transmembrane activator and calcium modulator and cyclophilin ligand (CAML) interactor TACI, whereas APRIL binds to a third receptor heparin sulfate proteoglycans (HSPGs) and BAFF binds to a third receptor BAFFR (also known as BR3) ${ }^{[23-25]}$.

In animal models, APRIL and BAFF show a tumorpromoting activity, as their overexpression induces development of B cell neoplasia ${ }^{[26,27]}$. However, APRIL tumor-promoting activity is not restricted to B cell lymphomas. Indeed, APRIL was also shown to provide a proliferative/survival signal to solid tumor cells. Although modestly detectable in vitro, this activity has been observed significantly in vivo by overexpressing APRIL in tumor cells or by blocking endogenous APRIL ${ }^{[4,10,28]}$.

RNA interference (RNAi), discovered in 1998 by Fire et al, has recently emerged not only as a powerful genetic tool for studying gene functions, but also for developing highly specific drugs by posttranscriptional silencing of gene expression ${ }^{[29,30]}$. The effective delivery of siRNA molecules into target cells or tissues is critical

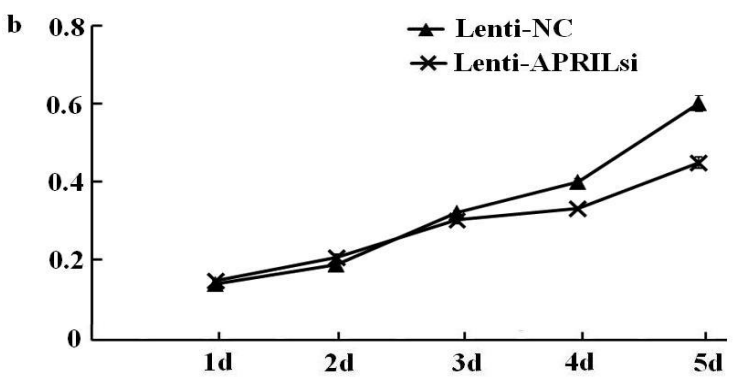

Fig. 3: Effect of lenti-APRILsi and lenti-NC on viability of MGC-803 and SGC-7901 cells The effects of $(-\times-)$ Lenti-APRILsi and $(-\Delta-)$ lenti-NC on the viability of a. MGC-803 and b. SGC-7901 cells. Viability was detected using MTT assay 
www.ijpsonline.com

a

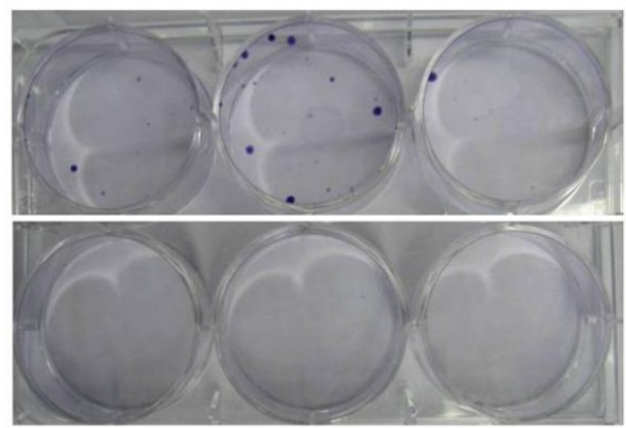

MGC-803

c

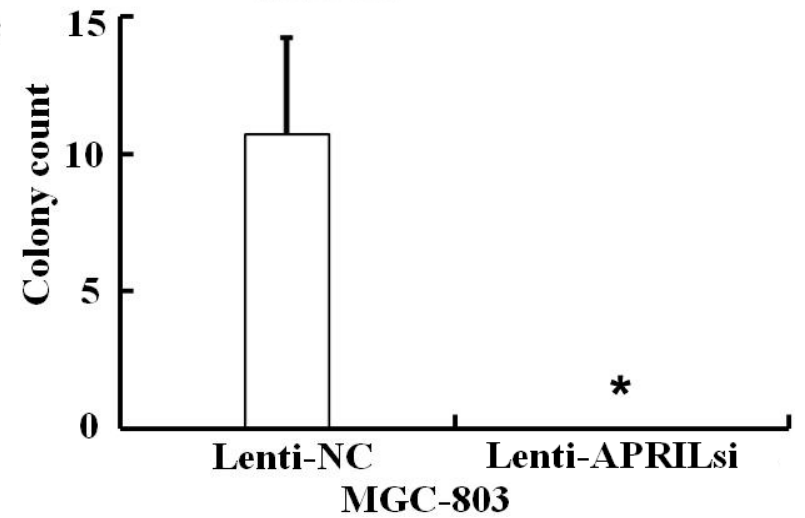

Lenti-NC b

Lenti-APRILsi

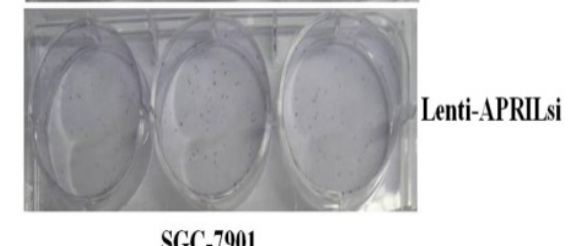

d

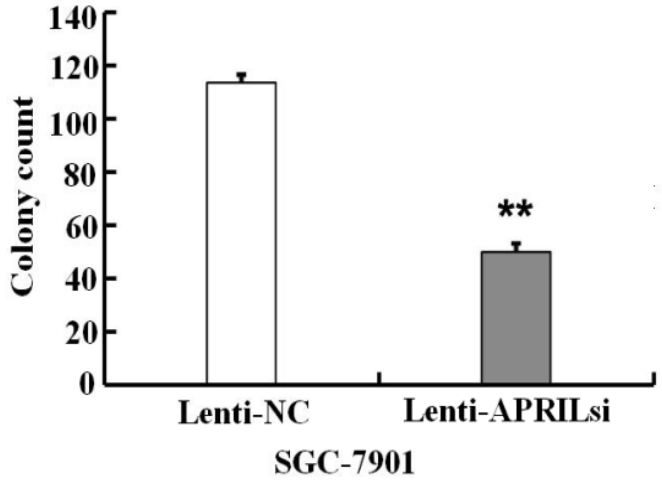

Fig. 4: Colony formation in lenti-NC- and lenti-APRILsi-infected MGC-803 and SGC-7901 cells Colony formation in a. and c. lenti-NC and lenti-APRILsi-infected MGC-803 and b. and d. SGC-7901 cells. **represents $\mathbf{p}<0.01$ and *represents $\mathbf{p}<0.05$

a

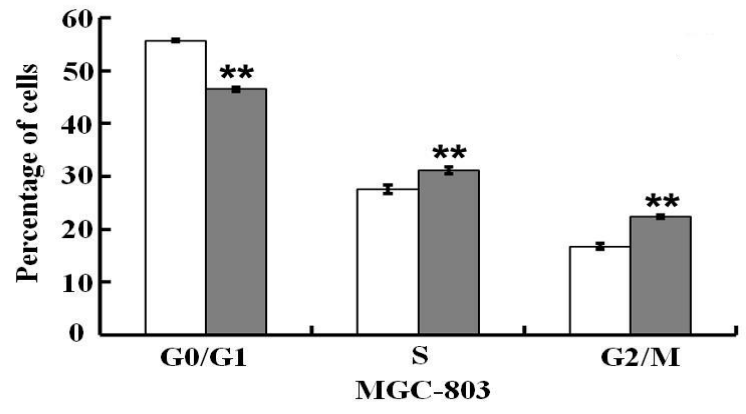

b

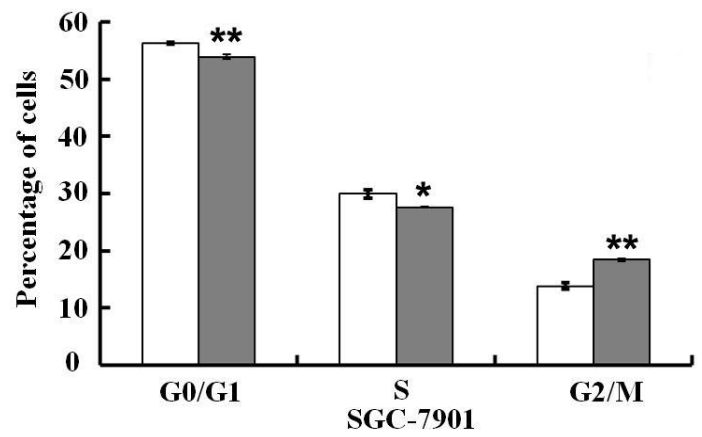

Fig. 5: Effects of lenti-APRILsi on MGC-803 and SGC-7901 cells.

Effects of lenti-APRILsi on the cell cycle of a. MGC-803 and b. SGC-7901 cells **represents $\mathbf{p}<0.01$ and *represents $p<0.05$. ( $\square$ ) lenti-APRILsi, ( $\square$ ) Lenti-NC

for successful RNAi application. The lentiviruses are a family of retroviruses that can integrate into the genomes of not only dividing cells but also non- dividing cells with high efficiency to achieve stable, long-term expression of shRNAs and thus have become one of the widely used delivery systems for exogenous genes transfer ${ }^{[31,32]}$.

In this study, it was demonstrated that lentiviruses could efficiently deliver APRIL-siRNA into MGC-803 and SGC-7901 cells. The infection of lenti-APRILsi not only greatly down-regulated the endogenous APRIL mRNA expression in both cell lines, but also reduced the cell viability and colony formation as detected in the MTT assay and colony formation assay, respectively, implying the siRNA sequences targeting APRIL could be a potential mode of gene therapy for GC. Moreover, silencing APRIL by siRNA leads to significant reduction of number $\mathrm{G}_{0} / \mathrm{G}_{1}$ phase cells and apparent increase of number of $\mathrm{G}_{2} / \mathrm{M}$ phase cells in both cell lines, indicating that lenti-APRILsi arrested the cell cycle at $\mathrm{G}_{2} / \mathrm{M}$ phase, thus lead to inhibition of cell proliferation.

Thus this study demonstrated that siRNA targeting of APRIL mRNA via a lentivirus vector system effectively inhibited the APRIL mRNA expression in MGC-803 and SGC-7901 cells, reduced the cell viability and colony formation, and further confirmed that lentiAPRILsi decreased the cell viability by arresting cell 
cycle at $\mathrm{G}_{2} / \mathrm{M}$ phase. However, this form of gene therapy is now limited to only to treat cancer and failure of such approach could worsen the condition. Incompatibility issues and immune responses could also lead to failure of therapy.

\section{Conflict of interest:}

The authors report no conflicts of interest in this work.

\section{REFERENCES}

1. Kamangar F, Dores GM, Anderson WF. Patterns of cancer incidence, mortality, and prevalence across five continents: Defining priorities to reduce cancer disparities in different geographic regions of the world. J Clin Oncol 2006;24:213750.

2. Cancer-Fact sheet $\mathrm{N}^{\circ}$ 297: World Health Organization. 2009;05-11.

3. Gastric cancer: Emedicine Medscape. 2009.

4. Hahne M, Kataoka T, Schroter M, Hofmann K, Irmler M, Bodmer JL, et al. APRIL, a new ligand of the tumor necrosis factor family, stimulates tumor cell growth. J Exp Med 1998;188:1185-90.

5. Lopez-Fraga M, Fernandez R, Albar JP, Hahne M. Biologically active APRIL is secreted following intracellular processing in the Golgi apparatus by furin convertase. EMBO Rep 2001;2:945-51.

6. Nardelli B, Belvedere O, Roschke V, Moore PA, Olsen HS, Migone TS, et al. Synthesis and release of B-lymphocyte stimulator from myeloid cells. Blood 2001;97:198-204.

7. Chu VT, Enghard P, Riemekasten G, Berek C. In Vitro and in vivo activation induces BAFF and APRIL expression in B Cells. J Immunol 2007; 79: 5947-59.

8. He B, Chadburn A, Jou E, Schattner EJ, Knowles DM, Cerutti A. Lymphoma B cells evade apoptosis through the TNF Family members BAFF/BLyS and APRIL. J Immunol 2004;172:326879.

9. Stein JV, Lopez-Fraga M, Elustondo FA, Carvalho-Pinto CE, Rodriguez D, Gomez-Caro R, et al. APRIL modulates B and T cell immunity. J Clin Invest 2002;109:1587-98.

10. Roth W, Wagenknecht B, Klumpp A, Naumann U, Hahne M, Tschopp J, et al. APRIL, a new member of the tumor necrosis factor family, modulates death ligand-induced apoptosis. Cell Death Difer 2001;8:403-10.

11. Pelekanou V, Kampa M, Kafousi M, Darivianaki K, Sanidas E, Tsiftsis DD, et al. Expression of TNF-superfamily members BAFF and APRIL in breast cancer: immunohistochemical study in 52 invasive ductal breast carcinomas. BMC Cancer 2008;8:76.

12. Deshayes F, Lapree G, Portier A, Richard Y, Pencalet P, Mahieu-Caputo D, et al. Abnormal production of the TNFhomologue APRIL increases the proliferation of human malignant glioblastoma cell lines via a specific receptor. Oncogene 2004;23:3005-12.

13. Chiu A, Xu W, He B, Dillon SR, Gross JA, Sievers E, et al. Hodgkin lymphoma cells express TACI and BCMA receptors and generate survival and proliferation signals in response to BAFF and APRIL. Blood 2007;109:729-39.

14. Moreaux J, Legouffe E, Jourdan E, Quittet P, Reme T, Lugagne $\mathrm{C}$, et al. BAFF and APRIL protect myeloma cells from apoptosis induced by interleukin 6 deprivation and dexamethasone. Blood 2004;103:3148-57.

15. Kern C, Cornuel JF, Billard C, Tang R, Rouillard D, Stenou $\mathrm{V}$, et al. Involvement of BAFF and APRIL in the resistance to apoptosis of B-CLL through an autocrine pathway. Blood 2004;103:679-88.

16. Yaccoby S, Pennisi A, Li X, Dillon SR, Zhan F, Barlogie $\mathrm{B}$, et al. Atacicept (TACI-Ig) inhibits growth of TACI high primary myeloma cells in SCID-hu mice and in coculture with osteoclasts. Leukemia 2008;22:406-13.

17. Kelly K, Manos E, Jensen G, Nadauld L, Jones DA. APRIL/ TRDL-1, a tumor necrosis factor-like ligand, stimulates cell death. Cancer Res 2000;60:1021-7.

18. Mao ZB, Zhang DL, Shi J, Huang JF, Wang WY, Meng XY. The role of the expression of a proliferation inducing ligand and its receptors in the gastric carcinogenesis. Chin J Dig 2005;25:476-9.

19. Zhang JF, Zhu HJ, Mao ZB, Xu Z, Pan ZP, Cai BH. Expression of APRIL and its receptors in gastric cancer tissues and its significance. Acad J Second Military Med Univ 2008;29:111921.

20. Zhang JF, Mao ZB, Xu Z, Zhu HJ, Zhang JG, Ni RZ. Pathological significance of expression of a proliferationinducing ligand and its receptors mRNAs in human gastric carcinoma. Acta Academiae Medicinae Nantong 2009;29:98103.

21. Nishitsuji H, Ikeda T, Miyoshi H, Ohashi T, Kannagi M, Masuda T. Expression of small hairpin RNA by lentivirusbased vector confers efficient and stable gene-suppression of HIV-1 on human cells including primary non-dividing cells. Microbes Infect 2004;6:76-85.

22. Resende C, Ristimäki A, Machado JC. Genetic and epigenetic alteration in gastric carcinogenesis. Helicobacter 2010;15:349.

23. Marsters SA, Yan M, Piti RM, Haas PE, Dixit VM, Ashkenazi A. Interaction of the TNF homologues BLyS and APRIL with the TNF receptor homologues BCMA and TACI. Curr Biol 2000;10:785-8.

24. Kalled SL, Ambrose C, Hsu YM. The biochemistry and biology of BAFF, APRIL and their receptors. Curr Dir Autoimmun 2005;8:206-42.

25. Ingold K, Zumsteg A, Tardivel A, Huard B, Steiner QG, Cachero $\mathrm{TG}$, et al. Identiication of proteoglycans as the APRIL-speciic binding partners. J Exp Med 2005;201:137583.

26. Planelles L, Carvalho-Pinto CE, Hardenberg G, Smaniotto S, Savino W, Gomez-Caro R, et al. APRIL promotes B-1 cellassociated neoplasm. Cancer Cell 2004;6:399-408.

27. Batten M, Fletcher C, Ng LG, Groom J, Wheway J, Laabi Y, et al. TNF deficiency fails to protect BAFF transgenic mice against autoimmunity and reveals a predisposition to B cell lymphoma. J Immunol 2004;172:812-22.

28. Rennert P, Schneider P, Cachero TG, Thompson J, Trabach L, Hertig S, et al. A soluble form of B cell maturation antigen, a receptor for the tumor necrosis factor family member APRIL, inhibits tumor cell growth. J Exp Med 2000;192:1677-84.

29. Fire A, Xu S, Montgomery MK, Kostas SA, Driver SE, Mello CC. Potent and specific genetic interference by double-stranded RNA in Caenorhabditis elegans. Nature 1998;391:806-11.

30. Wang H, Tan SS, Wang XY, Liu DH, Yu CS, Bai ZL, et al. Silencing living gene by siRNA leads to apoptosis induction, 
cell cycle arrest, and proliferation inhibition in malignant melanoma LiBr cells. Acta Pharmacol Sin 2007;28:1968-74.

31. Naldini L, Gallay P, Gallay P. In vivo gene delivery and stable transduction of nondividing cells by a lentiviral vector. Science 1996;272:263-7.

32. Fish RJ, Kruithof EK. Short-term cytotoxic effects and longterm instability of RNAi delivered using lentiviral vectors. BMC Mol Biol 2004;5:9.
This is an open access article distributed under the terms of the Creative Commons Attribution-NonCommercial-ShareAlike 3.0 License, which allows others to remix, tweak, and build upon the work non-commercially, as long as the author is credited and the new creations are licensed under the identical terms

This article was originally published in a special issue, "Biomedical research applications in Pharmaceutical Sciences"

Indian J Pharm Sci 2020:82(2)spl issue3;25-31 